\title{
Does anterolateral ligament injury change the treatment option in patients with partial ACL tears?
}

\begin{abstract}
Burak Gunaydin, Tugba Ilkem Kurtoglu Ozcaglayan, Mehmet Umit Cetin, Abdulkadir Sari, Yasar Mahsut Dincel, Cagatay TEKIN
\end{abstract}

From the Tekirdag Namik Kemal University Medical Faculty, Orthopaedics and Traumatology Department, Turkey

Patients with ACL tears with ALL injury have more clinical complaints (instability, feeling of the pop on the knee or knee sliding). patients have ALL injury with partial ACL tears, It is unclear whether the choice of treatment will be conservative or surgical.

This study aimed to determine the effect of anterolateral ligament (ALL) status, whether intact or ruptured, on the choice of conservative or surgical treatment in patients with partial anterior cruciate ligament (ACL) tears.

Between 2015 and 2019, patients with suspected partial ACL tears were identified on both physical examination and MR imaging. 122 patients who had partial ACL tears and also status of patient's ALL could be evaluated by radiologist were included in the study, retrospectively.

Sixty-two patients who underwent ACL reconstruction were determined as group 1 , and 60 patients who did not undergo ACL reconstruction were defined as group 2. In patients with partial ACLrupture with or without ACL reconstruction, it was evaluated whether a ruptured or nonruptured ALL was effective in this decision of conservative or surgically.

The MRIs of patients with partial ACL tears were evaluated by a radiologist and it was concluded

Authours declare that there is no conflict of interest or funding for this study. For this study, Ethics Committee approval dated 01/08/2019 and numbered 2019/132/08/04 was obtained from the Ethics Committee of Tekirdag Namık Kemal University Faculty of Medicine. Informed consent was obtained from all individual participants included in the study. This study has been registered retrospectively (Registration number:ChiCTR2000028788). that the ALLs of 50 patients were ruptured, and 72 were intact. The ALLs of 36 patients in group 1 were ruptured, and 26 patients were intact. Fourteen patients in group 2 had ruptured ALLs, 46 patient's ALLs were intact. Seventy-two percent of the patients with partial ACL tears who had ruptured ALLs in MRI underwent ACL reconstruction.

It was found that $\mathrm{ACL}$ reconstruction was performed more frequently in patients with partial ACL tears with ALL rupture. Therefore, we believe that preoperative evaluations of ALLs using MRI in patients with partial ACL tears are essential for surgical planning.

Keywords : anterior cruciate ligament; partial ACL tear; anterolateral ligament ; arthroscopic reconstruction; MRI.

- Burak Gunaydin¹, Md, Asst. Prof.

- Tugba Ilkem Kurtoglu Ozcaglayan², Md, Asst. Prof.

- Mehmet Umit Cetin ${ }^{1}$, Md, Asst.Prof.

- Abdulkadir Sari', Md, Asst. Prof.

- Yaşar Mahsut Dinçel' ${ }^{1}, \mathrm{Md}$, Asst. Prof.

- Cagatay Tekin ${ }^{3}, \mathrm{Md}$, Expert

${ }^{1}$ Tekirdag Namik Kemal University Medical Faculty, Orthopaedics and Traumatology Department, Turkey

${ }^{2}$ Tekirdag Namik Kemal University Medical Faculty, Radiological Department, Turkey

${ }^{3}$ Strnak Cizre State Hospital Orthopaedics and Traumatology Department, Turkey

Correspondence : Burak Gunaydin, Tekirdag Namik Kemal University Medical Faculty, Orthopaedics and Traumatology Department, Namık Kemal District Kampus street 1/14, 59100, Süleymanpasa, Tekirdag, Turkey.

Email : docburak@gmail.com

- 2021, Acta Orthopædica Belgica.

Acta Orthopædica Belgica, Vol. 87 - 2 - 2021 


\section{INTRODUCTION}

The prevalence of knee ligament injuries increases in parallel with the rise in the number of people engaged in sports activities, and ACL injuries are the most common. ACL tears are divided into two as total and partial. There is no consensus on the criteria for the diagnosis of a partial ACL tears (1). Partial ACL tears should suggest the detection of low-grade laxity in measurements with a KT1000 device, non-symmetric Lachman test $(<3 \mathrm{~mm})$, a negative pivot shift test (PST). In arthroscopic evaluations, although the ACL's integrity has deteriorated, lack of full-thickness should be detected (2). Partial ACL tears are present in 38\% of ACL tears (3), so some authors recommend surgery $(4,5)$, as well as conservative treatment with goodexcellent functional results $(3,6)$. In the study by Sonnery-Cottet et al., ways to treat partial ACL tear were described (1).

The anterolateral ligament (ALL) was also shown to contribute to stability together with the ACL of the knee (7-10). The ALL provides significant stability against anterolateral tibial rotation (11).

Patients with ACL tears with ALL injury have more clinical complaints (instability, feeling of the pop on the knee or knee sliding). patients have ALL injury with partial ACL tears, It is unclear whether the choice of treatment will be conservative or surgical.

In this study, we aimed to retrospectively determine whether the intact or ruptured ALL of the patients with partial ACL tears has an effect on conservative or surgical treatment selection. If In patients with partial ACL rupture, the effect of AL ligament on whether ACL reconstruction is performed is unknown. We hypothesize that ACL reconstruction is performed more frequently in patients with partial ACL tears accompanied by ALL rupture.

\section{MATERIALS AND METHODS}

The Local Ethics Committee approved this study (Date : 01/08/2019, No :2019/132/08/04).

Between 2015 and 2019, 205 patients with a suspected partial ACL rupture performed physical examination by Lachman, anterior drawer test, and were recorded as partial ACL rupture on magnetic resonance imaging (MRI) were identified. After a radiologist examined the ALLs of these patients using MRI, 122 patients whose ALLs were intact or ruptured and had at least 1-year follow-up were included in the study, retrospectively. The Lachman test was less than $3 \mathrm{~mm}$ and asymmetrical compared with the other side in these patients. The passive Lachman, anterior drawer, and PSTs were performed on the patients during their preop and final follow-ups. Lachman, anterior drawer test, and PST were found to be negative, or 1 positive, and no patient was found to be 2-3 positive in the patients after preoperative anesthesia.

Patients with partial ACL tears feel insecure and weak in their knees during strenuous sports and activities, while they can perform their daily work that does not require effort without complaints.

The surgery of these patients was performed by two experienced orthopedic surgeons who were experts in sports orthopedic surgery. Thus, the diagnosis of partial tears was made in arthroscopy. However, only a single orthopedist does a physical examination of patients.

The PST and Lachman test were found as 1 positive in the patients under anesthesia. ACL reconstruction was performed when the decision was taken at the surgery for ruptured more than $50 \%$ of the ACL.

Accordingly, the tip of inspection probe was used as a scale and $50 \%$ tear decision was made with the diameter of the intact fibers of the ACL. In the measurement made with the probe, those below 5 $\mathrm{mm}$ were considered as ACL tears over $50 \%$.

Inclusion criteria in this study were follow-up for more than 1 year, over the age of 16 and under the age of 40, and radiologists could evaluate patients whose ALL and ACLs with MRI.

Patients who were not diagnosable for ALL status using MRI by a radiologist, with total ACL tears in MRI, and at the same time with more than $5 \mathrm{~mm}$ Lachman at the physical examination, were considered as having complete ACL tears and were excluded from the study.

Patients with a follow-up of less than one year, multiple ligament injuries, and RAMP lesions 
were excluded from the study. Patients who had arthroscopic surgery before on the same knee, Revision ACL surgeries, patients who had a femur or tibia fracture in the same lower limb, and patients with a deformity in their lower limbs were also excluded.

One hundred twenty-two patients with partial ACL tears were divided into two groups according to whether performed ACL reconstruction or not. Determined Sixty-two patients who underwent ACL reconstruction as group 1, and 60 patients who did not undergo ACL reconstruction were considered group 2. The evaluation of 122 patients was retrospective. Therefore, the surgeon who performed the arthroscopic knee surgery was unaware of whether the ALLs of the patients were intact or ruptured in MRIs because the two orthopedic surgeons who performed arthroscopic surgery did not have the experience to interpret MRIs by evaluating ALL rupture before the surgery. Radiologists do not routinely evaluate AL ligament during MRI reporting. A radiologist evaluated the ALLs as intact or ruptured in preoperative MRIs retrospectively without knowing the patient's physical examination and treatment method of ACL for this study.

How and whether ACL reconstruction was performed according to ALL damage during the arthroscopic surgery of patients with partial ACL rupture was evaluated statistically.

In the study, statistical analyses were performed using the Statistical Package for the Social Sciences (SPSS, Chicago, Illinois, USA), version 23.0 software. First, data were tested for normal distribution using the Kolmogorov-Smirnov Z test. The groups' means were compared using Student's t-test for normally distributed data and the MannWhitney $U$ test for non-normally distributed data. In the comparison of qualitative data, Pearson's Chi-square test and Fisher's exact test were used. The results were evaluated at a significance level of $p<0.05$. Age, sex, duration of follow-up, side of lesion, meniscus and cartilage lesions and performed treatment options, Lysholm activity score, IKDC subjective knee evaluation form, thigh atrophy, and range of knee joint motion were comparatively evaluated between the two groups.

\section{RESULTS}

One hundred twenty-two patients with partial ACL tears were divided into two groups according to whether ACL reconstruction was performed. Sixty-two patients underwent ACL reconstruction and were determined as group 1, and 60 patients did not undergo ACL reconstruction and were considered group 2.

Among the 122 patients with partial ACL tears, it was identified by the radiologist that the ALLs of 50 patients were ruptured, and 72 patients' ALLs were intact.

It was found that the ALLs of 36 patients in group 1 were ruptured, whereas 26 patients' ALLs in this group were intact. The ALL of 14 patients in group 2 were ruptured, and 46 patients' ALLs in group 2 were intact $(\mathrm{p}<0.01)$ (Table 1$)$.

In group 1, 45 patients had an anteromedial bundle rupture, and 21 patients had a posterolateral

Table 1. - ALL status of the patients with ACL partial tears, sex, and side distribution in the groups

\begin{tabular}{|c|c|c|c|c|}
\hline Partial ACL tears & & $\begin{array}{c}\text { ACL } \\
\text { Reconstruction } \\
\text { Group 1 } \\
(n=62)\end{array}$ & $\begin{array}{c}\text { No ACL } \\
\text { Reconstruction } \\
\text { Group } 2 \\
(n=60)\end{array}$ & $P$ \\
\hline \multirow[t]{2}{*}{ ALL status } & ALL Ruptured & $36(58.06 \%)$ & $14(23.3 \%)$ & \multirow[t]{2}{*}{$<0.01$} \\
\hline & ALL Intact & $26(41.93 \%)$ & $46(76.6 \%)$ & \\
\hline \multirow[t]{2}{*}{ Sex } & Male & $55(88.7 \%)$ & $51(85 \%)$ & \multirow[t]{2}{*}{0.6} \\
\hline & Female & $7(11.29 \%)$ & $9(15 \%)$ & \\
\hline \multirow[t]{2}{*}{ Side } & Right & $33(53.22 \%)$ & $31(51.66 \%)$ & \multirow[t]{2}{*}{0.86} \\
\hline & Left & $29(46.77 \%)$ & $29(48.33 \%)$ & \\
\hline
\end{tabular}


Table 2. - Mean age and length of follow-up of the patients with ACL partial tears in the groups

\begin{tabular}{|c|c|c|c|}
\hline & $\begin{array}{c}\text { ACL Reconstruction } \\
\text { Group } 1 \\
(n=62) \\
\text { Mean } \pm \text { SD (range) }\end{array}$ & $\begin{array}{c}\text { No ACL Reconstruction } \\
\text { Group } 2 \\
(\mathbf{n}=60) \\
\text { Mean } \pm \text { SD (range) }\end{array}$ & $P$ \\
\hline Age (years) & $28.40 \pm 6.47(18-39)$ & $28.27 \pm 6.91(17-38)$ & 0.86 \\
\hline $\begin{array}{l}\text { Length of follow-up } \\
\text { (months) }\end{array}$ & $19.74 \pm 6.85(12-36)$ & $19.13 \pm 6.50(12-35)$ & 0.63 \\
\hline
\end{tabular}

Table 3. - Lysholm activity score, IKDC subjective knee evaluation form, knee joint range of motion, and differences between average thigh diameters of the patients with ACL partial tears

\begin{tabular}{|l|c|c|c|}
\hline & $\begin{array}{c}\text { ACL Reconstruction } \\
\text { Group 1 (n=62) } \\
\text { Mean } \pm \text { SD (range) }\end{array}$ & $\begin{array}{c}\text { No ACL Reconstruction } \\
\text { Group 2 (n=60) } \\
\text { Mean } \pm \text { SD (range) }\end{array}$ & $P$ \\
\hline Lysholm activity score average & $96.23 \pm 4.01(86-100)$ & $95.88 \pm 4.06(85-100)$ & $\mathbf{0 . 6 6 2}$ \\
\hline $\begin{array}{l}\text { IKDC subjective knee evaluation } \\
\text { form averange }\end{array}$ & $93,97 \pm 5.15(84-100)$ & $94.18 \pm 4.33(85-100)$ & $\mathbf{0 . 9 2 6}$ \\
\hline Knee joint range of motion $\left(^{\circ}\right)$ & $135.9 \pm 10.1(120-150)$ & $139.3 \pm 10.3(120-160)$ & $\mathbf{0 . 0 6 4}$ \\
\hline $\begin{array}{l}\text { Difference between thigh } \\
\text { diameters average }(\mathbf{c m})\end{array}$ & $0.99 \pm 0.79(0-2.5)$ & $0.85 \pm 0.72(0-2)$ & $\mathbf{0 . 3 4 6}$ \\
\hline
\end{tabular}

Table 4. - Meniscus and cartilage findings identified in the arthroscopic knee surgery of the patients with ACL partial tears

\begin{tabular}{|l|l|c|c|c|}
\hline \multicolumn{2}{|c|}{ Lesion } & $\begin{array}{c}\text { ACL Reconstruction } \\
\text { Group 1 } \\
\text { (n=62) }\end{array}$ & $\begin{array}{c}\text { No ACL Reconstruction } \\
\text { Group 2 } \\
(\mathbf{n = 6 0 )}\end{array}$ & \multirow{2}{*}{} \\
\hline \multirow{2}{*}{ Meniscal lesion } & Medial Meniscus & $32(51.61 \%)$ & $35(58.33 \%)$ & \multirow{2}{*}{$\mathbf{0 . 6 4}$} \\
\cline { 2 - 4 } & Lateral Meniscus & $22(35.48 \%)$ & $20(33.33 \%)$ & \\
\cline { 2 - 4 } Chondral lesion & Intact Meniscus & $8(12.9 \%)$ & $5(8.33 \%)$ & \multirow{2}{*}{$\mathbf{0 . 9 3}$} \\
& Chondral injury & $10(16.12 \%)$ & $50(16.66 \%)$ & \\
\cline { 2 - 4 } & $\begin{array}{l}\text { Intact chondral } \\
\text { tissue }\end{array}$ & $52(87.09 \%)$ & $53.33 \%)$ & \\
\hline
\end{tabular}

Table 5. - Distribution of repair or partial meniscectomy applied to meniscus pathologies of the patients with meniscus tears

\begin{tabular}{|l|l|c|c|}
\hline & & $\begin{array}{c}\text { Meniscus lesion } \\
\text { Group 1 (n=54) }\end{array}$ & $\begin{array}{c}\text { Meniscus lesion } \\
\text { Group 2 (n=55) }\end{array}$ \\
\hline \multirow{2}{*}{$\begin{array}{l}\text { Medial } \\
\text { Meniscus }\end{array}$} & Meniscal Repair & $25(46.29 \%)$ & $25(45.45 \%)$ \\
\cline { 2 - 4 } $\begin{array}{l}\text { Lateral } \\
\text { Meniscus }\end{array}$ & Martial meniscectomy & $7(12.96 \%)$ & $10(18.18 \%)$ \\
\cline { 2 - 4 } & Partial meniscectomy & $15(27.77 \%)$ & $15(27276 \%)$ \\
\hline
\end{tabular}

bundle rupture. Four-strand ACL reconstruction was performed to patients with partial tears, using the hamstring tendons of that ligament, whichever ligament was torn. During reconstruction, we choose to preserve the intact bundle of the ACL to protect it as much as possible.

The results of age, sex, duration follow-up, side of lesion, Lysholm activity, the IKDC subjective knee 
Table 6. - Distribution of localization of chondral injury and surgical treatment performed according to the groups of the patients with chondral injury in the groups

\begin{tabular}{|l|l|c|c|}
\hline & & $\begin{array}{c}\text { Chondral injury } \\
\text { Group 1 (n=10) }\end{array}$ & $\begin{array}{c}\text { Chondral injury } \\
\text { Group 2 (n=10) }\end{array}$ \\
\hline Medial Femoral Condyle & Microfracture & $5(50 \%)$ & $4(40 \%)$ \\
\hline Lateral Femoral Condyle & Microfracture & $5(50 \%)$ & $6(60 \%)$ \\
\hline
\end{tabular}

assessment form, and knee joint range of motion measurement, meniscus tears, chondral lesions, treatment option of the meniscus and chondral lesions, and also the difference in values in the comparisons between thigh diameters showed no statistically significant differences $(\mathrm{p}<0.05)$ (Table $1,2,3,4,5,6)$.

In one patient who had partial ACL rupture and underwent ACL reconstruction, washing and debridement were performed after determining an infection in the early period. In the follow-up, two patients had to undergo ACL revision surgery because of graft failure, whose primary ACL reconstruction was previously performed with partial ACL ruptures. In two patients with intact ALLs and partial ACL rupture, ACL reconstruction was performed due to the partial ACL rupture becoming a total rupture. All these patients were excluded from the study because of the effect on the results.

When the relation between the performance of ACL reconstruction to patients with partial ACL tears and ALL rupture was examined, it was found the sensitivity and specificity were $72 \%$ and $63.8 \%$, respectively, and the positive and negative predictive values were $58.06 \%$ and $76.6 \%$, respectively.

Seventy-two percent of the patients with partial ACL tears who had ruptured ALLs in MRI underwent ACL reconstruction. Fourteen (23.3\%) patients had a partial ACL tear and ruptured ALL in MRI but did not undergo ACL reconstruction. In patients with partial ACL rupture, it must be clarified that ALL rupture was associated with performing ACL reconstruction. In other words, ACL reconstruction was performed frequently in patients with partial ACL rupture who also had ALL injury; ACL reconstruction was performed less often in patients with ACL partial rupture without ALL damage.

\section{DISCUSSION}

Surgical treatment was used more frequently in patients with partial ACL tears who have underlying ALL tears. In this publication, the ACL was evaluated arthroscopically, and reconstruction was applied to the patients with partial ACL ruptures with more than $50 \%$ of the ACL tears. Conservative treatment was applied to those with tears below $50 \%$. MRIs of all these patients were evaluated retrospectively by the radiologist, and it was found that ALL were ruptured more frequently in patients who underwent ACL reconstruction. The strengths of this publication are that patient examinations are carried out by a single orthopedist. It is the first publication evaluating the status of ALL in patients with a partial ACL tear.

The definition of partial ACL rupture and treating surgical or conservative methods remain controversial (1). Completion of partial ACL rupture, which was followed by conservatively, was observed (3). For this reason, patients with partial tears and also ALL damage will increase completion of the ACL rupture with new traumas. When the partial ACL rupture turns to total ACL rupture, in patients with ALL injury, ALL reconstruction should be added to the ACL reconstruction in patients with ALL damage (12).

Although the number of bundles that make up the ACL in recent publications is controversial, the general acceptance is that there are two (1). The definition of partial ACL rupture is also controversial (1). Partial tears are defined as one of the anteromedial (AM) and posterolateral (PL) bundles being intact when the other bundle is ruptured ; it is also defined as the continuity of some of the tendons between the femoral and tibial attachment of the ACL (13). For the diagnosis of a partial tear, first, it should be suspected in the physical examination. Then, it is 
evaluated with MRI, which is an advanced imaging method.

In general terms, it was emphasized that MRI findings might suggest a partial ACL tear ; however, it has been shown in many publications that this is not sufficient to make a final diagnosis (12-15). In a study by Alioto et al., it was revealed that orthopedic surgical intervention plans changed due to MRI findings in $18 \%$ of patients (16).

The sensitivity and specificity of the tests used in the physical examinations of patients are different. The sensitivity of the Lachman test is $87 \%$, and its specificity is $93 \%$, whereas the sensitivity of the anterior drawer test is $48 \%$, and its specificity is $93 \%$. The sensitivity of the PST is $61 \%$, but its specificity is $97 \%$. Of these three tests, the PST has the highest positive predictive value (17). We used these three tests in outpatient follow-up and before arthroscopic surgery. In our patients, we found pivot test 1 positive and Lachman test 1 positive under anesthesia.

The results of the pivot and Lachman test performed on patients vary depending on the hemarthrosis and reactive synovitis in the knee. The protective muscle action effect of the hamstrings secondary to joint pain also contributes to the variations of tests. Different results can be obtained in the physical examination performed at different times (18).

In recent studies, it was emphasized that reasonable knee rotation control could not be achieved with current ACL reconstruction methods $(19,20)$. Therefore, as a result of research, the ALL was particularly useful in knee rotational stability $(21,22)$. However, in another recent study, it was reported that ALL rupture harmed functional scores and physical activity after single-bundle ACL reconstruction (23).

Zhang et al. divided patients into three groups, and they added single-bundle reconstruction to group 1, double-bundle reconstruction to group 2, and ALL reconstruction to group 3. They concluded that the combination of anatomic ALL reconstruction and ACL reconstruction increased the postoperative clinical outcomes (24). Many ALL reconstruction techniques have been described, and promising early results are reported in clinics that use the method (25-27). However, it is emphasized in current publications that many studies are needed to describe the ideal technique. Single bundle reconstruction was done patient with partial ACL tears ; no ALL reconstruction was performed in this study.

In a publication by Helito et al., as a result of MRI evaluations of adolescent patients with acute ACL tears, it was found that there was ALL rupture at a rate of $60.2 \%$ (28). In the present study, ALL rupture was found at a rate of $40 \%$ in patients with partial ACL tears in MRI.

In this study, patients with partial ACLruptures and also ALL ruptures were evaluated retrospectively ; performing ACL reconstruction in these patients was more frequent and statistically significant. If the ALL is intact in patients with partial ACL tears, the possibility of ACL reconstruction decreases due to there being more stability.

The present study has limitations, including the low number of patients, its retrospective design, and the short follow-up period. The patient's age is included only in this publication; other variables have not been included in this study; this is another limitation. An experienced radiologist needs to evaluate the ALL on MRI correctly. Naturally, many factors are active when deciding the treatment option for patients with partial ACL ruptures; additional injuries of the patient, sportive expectations, patient's age, athletic level, socioeconomic level, and patient's expectations are essential. As a result, many different parameters are valid when planning arthroscopic knee surgery. In this study, we evaluated only ALL damage and tried to examine the effect of patients with partial ACL rupture. Future studies that examine the impact of ALL in patients with partial tears are needed.

\section{CONCLUSIONS}

It was observed that ACL reconstruction was applied more frequently in patients with partial ACL tears who have underlying ALL tears. Therefore, we believe that preoperative evaluations of ALLs using MRI in patients with partial ACL tears are essential for surgical planning. Surgical treatment should be considered in the first place in patients 
with a combination of partial ACL and AL ligament rupture.

\section{REFERENCES}

1. Sonnery-Cottet B, Colombet P. Partial tears of the anterior cruciate ligament. Orthop Traumatol Surg Res. 2016; 102(Suppl. 1) : 59-67.

2. DeFranco MJ, Bach BR Jr. A comprehensive review of partial anterior cruciate ligament tears. J Bone Joint Surg Am 2009) ; 91 : 198-208.

3. Noyes FR, Mooar LA, Moorman CT 3rd, McGinniss GH. Partial tears of the anterior cruciate ligament. Progression to complete ligament deficiency. J Bone Joint Surg Br 1989 ; 71 : 825-833.

4. Kocher MS, Micheli LJ, Zurakowski D, Luke A. Partial tears of the anterior cruciate ligament in children and adolescents. Am J Sports Med. 2002 ; 30 : 697-703.

5. Hole RL, Lintner DM, Kamaric E, Moseley JB. Increased tibial translation after partial sectioning of the anterior cruciate ligament. The posterolateral bundle. Am J Sports Med. 1996 ; 24 : 556-560.

6. Sommerlath K, Odensten M, Lysholm J. The late course of acute partial anterior cruciate ligament tears. A nine to 15-year follow-up evaluation. Clin Orthop Relat Res 1992 ; $281: 152-158$.

7. Musahl V, Herbst E, Burnham JM, Fu FH. The anterolateral complex and anterolateral ligament of the knee. $J$ Am Acad Orthop Surg. 2018 ; 26 : 261-267.

8. Zaffagnini S, Grassi A, Marcheggiani Muccioli GM, Raggi F, Romagnoli M, Bondi A, et al. The anterolateral complex and anterolateral ligament of the knee. The anterolateral ligament does exist an anatomic description. Clin Sports Med 2018 ; 37 : 9-19.

9. Inderhaug E, Williams A. Do we need extra-articular reconstructive surgery? Clin Sports Med. 2018 ; 37 : 61-73.

10. Mathew M, Dhollander A, Getgood A. Anterolateral ligament reconstruction or extra-articular tenodesis : Why and when? Clin Sports Med 2018 ; 37 : 75-86.

11. Sonnery-Cottet B, Daggett M, Helito CP, Fayard JM, Thaunat M. Combined Anterior Cruciate Ligament and Anterolateral Ligament Reconstruction. Arthrosc Tech Oct. $2016 ; 31 ; 5(6): 1253-1259$.

12. Umans H, Wimpfheimer O, Haramati N, Applbaum YH, Adler M, Bosco J. Diagnosis of partial tears of the anterior cruciate ligament of the knee : value of MR imaging. AJR Am J Roentgenol. $1995 ; 165$ : 893-897.

13. Sonnery-Cottet B, Panisset JC, Colombet P. et al., French Arthroscopy Society (SFA) Partial ACL reconstruction with preservation of the posterolateral bundle. Orthop Traumatol Surg Res. 2012 ; 98 (Suppl. 8) : 165-170.

14. Hong SH, Choi JY, Lee GK, Choi JA, Chung HW, Kang HS. Grading of anterior cruciate ligament injury. Diagnostic efficacy of oblique coronal magnetic resonance imaging of the knee. J Comput Assist Tomogr. 2003 ; 27 : 8148-19.

15. Yao L, Gentili A, Petrus L, Lee JK. Partial ACL rupture : an MR diagnosis? Skeletal Radiol. 1995 ; 24 : 247-251.

16. Alioto RJ, Browne JE, Barnthouse CD, Scott AR. The influence of MRI on treatment decisions regarding knee injuries. Am J Knee Surg. 1999 ; 12 : 91-97.

17. Jackson JL, O'Malley PG, Kroenke K. Evaluation of acute knee pain in primary care. Ann. Intern. Med. 2003 ; 139(7) : 575-588.

18. Huang W, Zhang Y, Yao Z, Ma L. Clinical examination of anterior cruciate ligament rupture : a systematic review and meta-analysis. Acta Orthop Traumatol Turc. 2016 ; 50(1) : 22-31.

19. Hussein M, van Eck CF, Cretnik A, Dinevski D, Fu FH. Prospective randomized clinical evaluation of conventional single-bundle, anatomic single-bundle, and anatomic double-bundle anterior cruciate ligament reconstruction : 281 cases with 3- to 5-year follow-up. Am J Sports Med. $2012 ; 40: 512-520$.

20. Hussein M, Van Eck CF, Cretnik A, Dinevski D, Fu FH. Individualized anterior cruciate ligament surgery : A prospective study comparing anatomic single- and double bundle reconstruction. Am J Sports Med 2012 ; 40 : 17811788.

21. Thein R, Boorman-Padgett J, Stone K, Wickiewicz TL, Imhauser CW, Pearle AD. Biomechanical assessment of the anterolateral ligament of the knee : a secondary restraint in simulated tests of the pivot shift and of anterior stability. J Bone Joint Surg Am. 2016 ; 98 : 937-943.

22. Bonanzinga T, Signorelli C, Grassi A, Lopomo N, Bragonzoni L, Zaffagnini S, et al. Kinematics of ACL and anterolateral ligament. Part I : Combined lesion. Knee Surg Sports Traumatol Arthrosc. 2017 ; 25 : 1055-1061.

23. Gunaydin B, Turgut A, Sari A, Tekin C, Kilinc BE, Kusak I, et al. Does anterolateral ligament rupture affect functional outcomes in patients who underwent an anterior cruciate ligament reconstruction? Int J Surg. 2019 ; 65 : 2531.

24. Zhang H, Qiu M, Zhou A, Zhang J, Jiang D. Anatomic Anterolateral Ligament Reconstruction Improves Postoperative Clinical Outcomes Combined with Anatomic Anterior Cruciate Ligament Reconstruction. J Sports Sci Med. 2016 ; 15(4) : 688-696.

25. Wagih AM, Elguindy AM. Percutaneous Reconstruction of the Anterolateral Ligament of the Knee With a Polyester Tape. Arthrosc tech. 2016 ; 5(4) : 691-697.

26. Lutz C, Sonnery-Cottet B, Imbert P, Barbosa NC, Tuteja S, Jaeger JH. Combined Anterior and Anterolateral Stabilization of the Knee with the Iliotibial Band. Arthrosc Tech. $2016 ; 5(2): 251-256$.

27. Zein AMN, Elshafie M, Elsaid ANS, Elrefai MAE. Combined Anatomic Anterior Cruciate Ligament and Double Bundle Anterolateral Ligament Reconstruction. Arthrosc Tech. 2017 ; 6(4) : 1229-1238. 
28. Helito CP, Helito PVP, Assirati LFB, Longo CH, Bordalo-Rodrigues M, Souza FF. Magnetic resonance imaging evaluation of the anterolateral ligament in acute anterior cruciate ligament injuries in an adolescent population. Arthroscopy. $2019 ; 35: 2136-2142$. 